\title{
Filosofia e literatura
}

\author{
Jeanne Marie Gagnebin ${ }^{1}$
}

Resumo: Num primeiro momento, o artigo tenta reconstruir rapidamente as relações históricas entre filosofia e literatura a partir de sua origem platônica, na oposição entre o discurso da filosofia (uma palavra criada por Platão) e o discurso da poesia, da retórica ou daquilo que Platão chama de sofística. Num segundo, coloca em questão as dicotomias estabelecidas por essa separação, tais como sensível-inteligível, mentiraverdade e, finalmente, metáfora e conceito. Tenta mostrar a importância do sensível e das narrativas ficcionais (ou míticas) na própria filosofia de Platão e introduz a questão das relações entre linguagem e mundo como temática central do indizível a partir da crítica platônica da escrita. Essa temática é desenvolvida nas suas abordagens distintas entre o olhar retrospectivo da filosofia e o olhar mais profético da literatura, para recolocar a questão da ficção não em termos de mentira, mas, segundo Paul Ricoeur, como gesto mimético que reconfigura o real e permite, assim, a invenção imaginativa de outras possibilidades de realidade, invenção que nos faz pensar. Por fim, evoca rapidamente as "formas literárias" da filosofia, segundo os termos de Gottfried Gabriel, e sua significação para uma melhor compreensão do pensamento filosófico.

Palavras-chave: Literatura; filosofia; sensível; inteligível; ficção; reconfiguração.

Abstract: At first, this article attempts to quickly rebuild the historical relations between philosophy and literature from its Platonic origin, the opposition between the discourse of philosophy (a word created by Plato) and the poetry of speech, rhetoric or what Plato calls of sophistry. Then, it questions the dichotomies established by this separation, such as sensible-intelligible, truth-lie, and finally metaphor and concept. This papers tries to show the importance of sensitive and fictional (or mythical) narratives in the very philosophy of Plato and introduces the question of the relationship between language and the world as a central theme of the unutterable from the Platonic critique of writing. This theme is developed in his different approaches between the

1 É professora Titular da Pontifícia Universidade Católica (PUC-SP) e Livre- docente da Universidade Estadual de Campinas (Unicamp). 
hindsight of philosophy and the most prophetic view of literature, to bring the question of fiction back not in terms of lie, but according to Paul Ricoeur, as a mimetic gesture that reconfigures the real and thus allows the imaginative invention of other possibilities of reality, an invention that makes us think. Finally, this paper quickly evokes the philosophy's "literary forms", under the terms of Gottfried Gabriel, and its significance to a better understanding of the philosophical thought.

Keywords: Literature, philosophy, sensitive, intelligible, fiction, reconfiguration.

Agradeço pelo convite a participar desse encontro "Sofia" dos estudantes da Unifesp e pela presença de vocês hoje de noite. Deve haver algo de novo no ar, porque depois do convite de vocês, recebi mais dois outros que iam num sentido convergente: primeiro, da professora e amiga Arlenice que me pediu para participar de um número da revista do Departamento de filosofia da Unifesp, a "Limiar", cujo tema será, justamente, as relações entre filosofia e literatura; e há uns quinze dias, o mesmo convite chegou de um colega da Universidade Estadual de Feira de Santana na Bahia, ligado a uma revista interdisciplinar chamada "Sísifo", que também planeja um número sobre a mesma problemática.

Coincidências que eu gostaria de poder interpretar como uma abertura de vários setores da filosofia no Brasil a uma reflexão menos tímida sobre as relações que essa estranha disciplina - a filosofia - entretém com outras ciências humanas, sem por isso arriscar sua seriedade, seu rigor, enfim essa identidade tantas vezes austera e sisuda que, parece, deveria ser a nossa, estudantes e professores de filosofia. Fico feliz com essa abertura, se é que ela realmente existe, e a saúdo como um sinal de maturidade e de inventividade, sinal novo no Brasil, onde até agora tentamos muitas vezes fazer seriamente só história da filosofia, o que é ótimo, mas onde não ousávamos pensar, com mais liberdade a respeito da constituição histórica e linguística da própria filosofia. Quando digo "constituição histórica e linguística", digo duas coisas simples, mas que muitas vezes esquecemos: a primeira, que a filosofia se autodefine e é definida de diversas maneiras segundo os momentos de sua história, segundo os momentos $d a$ história: na Idade Média, tinha que se confrontar principalmente com a teologia, por exemplo, na modernidade, desde Descartes, com as matemáticas e com as ciências exatas, hoje com outras ciências ditas humanas ou naturais; a segunda coisa é que a 
filosofia só pode se dar na e pela linguagem, por isso a chamei de linguística ou de linguageira ("sprachlich"), ela não trabalha primeiramente com "ideias", mas sim com palavras. História e Linguagem, inseparáveis, delimitam o exercício filosófico, fazendo sua grandeza e sua fragilidade - e tecendo seu parentesco com aquilo que, a partir do Romantismo alemão, costumamos chamar de "literatura".

Proponho a vocês um itinerário em três passos principais a partir de textos que já publiquei $^{2}$, e que tomo a liberdade de aproveitar e de reformular para essa palestra. $\mathrm{O}$ primeiro passo é uma retomada da problemática em Platão, um passo autenticamente de história da filosofia, portanto! O segundo trata dos deslocamentos referenciais que a linguagem literária permite e encena, isto é, sobre as dimensões da imaginação, da ficção, da invenção, em termos platônicos, da mentira, deslocamentos que possibilitam a apreensão de outras dimensões da experiência humana. O terceiro, muito breve, convida a uma reflexão sobre "as formas literárias da filosofia", segundo a bela expressão do filósofo alemão Gottfried Gabriel.

Como podem perceber, não vou enveredar por um caminho muitas vezes trilhado, aquele das diferenças entre metáfora e conceito ou entre ilustração de um problema e formulação conceitual deste problema. Frequentemente, as aproximações filosóficas correntes buscam encontrar nos textos literários a ilustração sensível de conceitos filosóficos, procurando sob as diversas formas narrativas uma verdade mais "profunda", que o escritor somente saberia dizer de maneira indireta, mas que o filósofo se orgulha em nomear. Assim, o filósofo revelaria uma verdade mais fundamental, escondida sob os véus da fíç̧ão. Para permanecer em exemplos brasileiros, ele descobriria, assim, em Guimarães Rosa uma ética da tradição ou em Clarice Lispector uma concepção de angústia e de temporalidade que reenvia a Heidegger. Ao fazer isso, o filósofo reafirma as prerrogativas da reflexão filosófica, sua função essencial e fundadora, contra outras formas de linguagem e de saber. Ele reafirma igualmente uma concepção pobre, limitada e limitante, da literatura como um discurso ornamental e superficial, na melhor das hipóteses como uma retórica bem construída, um discurso que poderia se resolver e se dissolver numa outra maneira de dizer, talvez menos

2 Em particular: "Morte da memória, memória da morte", em Sete aulas sobre linguagem, memória e história, Imago, 1997; "As formas literárias da filosofia" em Lembrar escrever esquecer, Ed. 34, 2006; "Da dignidade ontológica da literatura" em Paul Ricoeur. Ética, identidade e reconhecimento, Ed. Loyola, São Paulo, 2013. 
agradável, todavia mais verdadeira, o discurso filosófico. À filosofia caberia o conceito, à literatura a imagem ou a metáfora.

Ora, é justamente essa separação entre inteligível e sensível que deve ser analisada e questionada. Mesmo Platão, que introduz essa dicotomia na reflexão, não o faz de maneira tão drástica como a tradição platônica costuma dizê-lo. Com efeito, se é claro que o céu das ideias está muito afastado de nosso cotidiano terreno, não conseguiríamos nem suspeitar sua presença fundante se não tivéssemos dele uma lembrança cintilante ou mesmo só um rastro confuso nesse cotidiano nosso. Como, diz Platão no Fedro, o amante lembra o amado ao ver sua túnica ou sua lira pendurada na parede, assim também lembramos das ideias divinas que vislumbramos na nossa vida anterior, antes de nascer. Sem lembrança da beleza celeste, não poderíamos reconhecer a beleza sensível, pois para Platão, como para uma boa parte da tradição filosófica, conhecer é, em primeiro lugar, reconhecer, portanto lembrar. E, na construção dos Diálogos, o sensível é o ponto imprescindível de partida para a viagem especulativa, seja a coceira na perna de Sócrates no início do Fédon ou o rolo de papiro que Fedro tenta disfarçar sob sua túnica no diálogo do mesmo nome. Como também, naturalmente, a beleza dos jovens rapazes como primeiro degrau sensível e físico na ascensão erótica até o Belo supremo no Banquete. Assim também, sempre na construção literária dos seus Diálogos, Platão/Sócrates lança mão de mitos, de imagens, de metáforas para ajudar seus interlocutores na compreensão de hipóteses e de raciocínios mais complicados.

A desconfiança de Platão em relação à poesia e a retórica, sua tentativa de distinguir radicalmente o discurso dos Sofistas e a atividade de Sócrates, esse estranho logos ao qual ele vai dar o nome de filosofia e que ele reivindica na sua própria prática de mestre e de escritor, todas essas tentativas não nascem, portanto, de uma condenação do sensível enquanto tal, mas de sua possível pretensão à autossustentação e à autossuficiência. Porque ele leva muitíssimo a sério a beleza da poièsis (um conceito amplo que também significa a poesia trágica nessa instituição cívica, política e artística que representa o teatro em Atenas), porque ele sabe o quanto gosta de teatro, poderíamos dizer, Platão fareja ali o perigo maior: que a sedução da beleza tenha mais força que a procura, muitas vezes difícil, ingrata, aporética, do verdadeiro. Esse perigo se concretiza nas manipulações dos demagogos (literalmente: aqueles que querem agradar ao povo em vez de educá-lo) na assembleia decisória da cidade e no ensino dos 
Sofistas que, segundo Platão/Sócrates, ajuda a solapar as antigas virtudes cívicas por argumentos retóricos tão brilhantes quanto vazios.

Se a querela entre filosofia e literatura vem de longa data, se ela marca o nascimento da própria filosofia com a luta de Platão contra a primazia da poesia homérica e contra a retórica daqueles que ele chama de Sofistas, devemos observar, portanto, que essa disputa sobre os diferentes poderes do discurso, do logos, se inscreve em Platão primeiramente no contexto de uma preocupação política de justiça (notadamente nas instituições da polis onde predomina o poder da palavra). É somente num segundo momento que tal confronto se distancia da questão política para se transformar em uma reivindicação do privilégio epistemológico do saber filosófico em detrimento de outras formas de pensamento.

Não quero com isso minimizar o impacto da exclusão dos poetas da cidade justa na República de Platão nem sua fundamentação "epistemológica”, no livro X, pela hierarquia entre modelo originário essencial (a famosa "ideia" da cama!), reprodução artesanal do modelo num objeto concreto e cópia artística tão perfeita quanto ilusória desse mesmo objeto, cópia de cópia, portanto, desprovida de qualquer densidade ontológica verdadeira. O que é instigante é justamente o poder emocional e evocativo de tal cópia vazia, o fato, como diz Platão, que choramos, mesmo homens feitos e virtuosos, não só mulheres e crianças débeis, quando vemos no palco essas cópias de sofrimentos pouco nobres (no Livro X da República ainda). É esse poder que faz problema porque a mímesis artística nos comove mais que o verdadeiro, a imagem mais que a "realidade", portanto introduz na ontologia um espaço indefinível que não é nem ser nem não-ser, o espaço da ilusão sedutora segundo Platão.

Como sabem, é esse estatuto enganador que funda, no fim do diálogo Fedro, a assim chamada "condenação da escrita" por Platão, condenação exposta através de um mito, de origem egípcia, diz Sócrates, isto é, uma origem muito antiga e muito respeitável, quando ele mesmo acaba de inventá-lo numa bela pirueta literária (mesmo Fedro, que não é tão inteligente assim, observa jocosamente essa facilidade de Sócrates em inventar mitos que lhe agradam!). Os caráteres escritos, inventados pelo jovem deus brincalhão Thot, enganam duplamente: primeiro, parecem um remédio contra o esquecimento quando, no fundo, são um veneno para memória verdadeira. A dupla significação da palavra pharmakon, remédio e veneno, foi analisada na sua pertinência 
ímpar por Derrida ${ }^{3}$ e caracteriza, já antes de Platão, essa força ambígua do canto poético que, simultaneamente, lembra do passado e faz esquecer da dor presente ${ }^{4}$. Em segundo lugar, os caracteres escritos se "assemelham perigosamente à pintura", imitam a vida, mas estão mortos, não respondem quando interrogados, continuam mudos $\mathrm{e}$ perigosamente belos nesse território enigmático onde morte e beleza se combinam, como no canto das Sereias. Platão diz algo, claro à revelia dele mesmo, que a "literatura', isto é a arte das "letras" (littera), não da voz viva, deverá explicitar bem mais tarde, em particular com Maurice Blanchot ${ }^{6}$ ou Bataille, Kafka ou Beckett, a saber que a raiz da literatura é a representação da ausência, por metonímia da morte e dos mortos. Não só porque, como no epos antigo, lembra as façanhas dos heróis mortos, mas porque escrever sempre significa abdicar da imediatidade da presença e da palavra viva.

Talvez seja uma das razões secretas que levou Platão a escrever tantos e tão belos diálogos, mesmo que condene a escrita em proveito do diálogo oral entre vivos. Prática funerária, a escrita permitiu a Platão erigir um túmulo de palavras a seu mestre Sócrates (que não escreveu nada), reabilitando sua memória, cuidando de sua "fama" ou "glória" (kleos) como fazia Homero com Hector, Aquiles ou Ulisses. Talvez quisesse também deixar como que relatos de discussões filosóficas, não para apresentar resultados ou mesmo uma doutrina, mas simplesmente modelos de exercícios especulativos. No segundo texto sempre citado, ao lado do Fedro, para tratar da "condenação" da escrita por Platão, na Carta Sétima, ao condenar, realmente, os “escritos" pretensamente filosóficos do tirano da Sicília, Dionísio, que se dizia seu discípulo, Platão no mesmo gesto desenvolve uma teoria da insuficiência dos signos (palavras, desenhos, até definições feitas de palavras) para apreender o ser verdadeiramente sendo (to on ontôs). Se, como afirma, a linguagem é fraca, doente 3 Jacques Derrida, A farmácia de Platão, Iluminuras, São Paulo, 1991.

4 Ver a droga usada porHelena no canto IV, verso 220, da Odisséia.

5 Fedro, 275 d.

6 Maurcie Blanchot, La littérature et le droit à la mort” in De Kafka à Kafka, Gallimard, Paris, 1981. 
(asthènes), isso, no entanto, não implica que dela devemos desistir. Pelo contrário, a filosofia consiste em exercícios espirituais incessantes ${ }^{7}$ que tem por alvo, não vencer o interlocutor nem chegar a um resultado definitivo, mas depois de muito treino, como depois de friccionar uma pedra contra outra, produzir uma faísca, fazer jorrar uma luz que não pode ser dita, mas que nos consola da fraqueza de nossas palavras. Continuemos, pois, a falar e mesmo a escrever, não tanto apesar das insuficiências da linguagem, mas muito mais em razão delas: na esperança que dessa fragilidade possa surgir como que uma ressonância ou um eco do verdadeiro real.

Platão introduz aqui um tema que atravessa toda nossa tradição, filosófica e literária, em particular poética: o tema duplo dos limites da linguagem e do indizível. Os limites da linguagem podem, em filosofia, nos levar a uma filosofia crítica de tipo kantiano, para justamente delimitar melhor o que está ao alcance ou não do nosso logos, linguagem e, simultaneamente, razão; ou, então, nos levar a uma teoria da contemplação e da iluminação (Platão, Plotino, Santo Agostinho, talvez Hegel?), na qual o tatear dos limites pode nos fazer como que gostar, num instante fugitivo, do sabor da transcendência. Não queria condenar uma filosofia tipo crítica em nome de outra, tipo mística, nem o contrário, mas gostaria de deixá-las coexistir, se corrigir e se completar mutuamente. Esse tema também é chave para toda a literatura, mesmo aquela que chamamos de realista, e não só nos artistas ditos loucos, como Hölderlin, mas também nos mais sensatos e comedidos, como Francis Ponge ou Manuel de Barros. Pois os limites da linguagem dizem respeito a um dos primeiros sentidos do assim chamado "indizível”, a saber, que não conseguimos descrever a relação entre nossa linguagem e o "mundo" ou o "real", porque, simplesmente, não podemos sair nem da linguagem nem do mundo para, como que num passo para trás, conseguir dizer como mundo e linguagem se correspondem - ou não. Essa relação sempre será um enigma, ela rigorosamente não pode ser dita.

Insisto nesse primeiro sentido do indizível, porque muitas vezes o termo recobre uma transcendência divina ou metafísica, quando se diz - com toda razão! - que nenhum adjetivo é capaz de qualificar Deus, aliás, nenhum nome tampouco. Esse emprego do termo é um signo de reverência diante da alteridade absoluta e caracteriza

7 Ver toda bela obra de Pierre Hadot sobre essa tradição da filosofia como exercício espiritual, de Platão a Wittgenstein: Exercices spirituels et philosophie antique, Albin Michel, 2002 et Wittgenstein et les limites du langage, Vrin, 2002. 
todas teologias negativas. Hoje também se usa o termo "indizível", em particular na teoria literária, quando se fala de momentos traumáticos, do sofrimento indizível das vítimas dos Campos de Concentração, por exemplo ${ }^{8}$. Mas justamente a existência dessa literatura demonstra que a impossibilidade da descrição e da fala não acarreta necessariamente o silêncio, como talvez se possa interpretar a partir de algumas afirmações do primeiro Wittgenstein. Pelo contrário: num escritor como Primo Levi, a necessidade da lembrança e da narração é uma exigência tão incisiva como o reconhecimento da essencial impossibilidade de tal descrição.

Talvez toquemos aqui uma das principais diferenças entre os domínios contíguos da literatura e da filosofia, da filosofia e da literatura. Podemos apreender essa diferença pela imagem da famosa coruja, pássaro de Minerva, isto é, de Atena, deusa da razão e padroeira dos filósofos. Como o diz Hegel (na Introdução à Filosofia do direito), a coruja levanta voo somente no crepúsculo, quando os acontecimentos barulhentos do dia já findaram. Pois a ambição da filosofia é entender o que aconteceu, nesse sentido encontrar uma chave, conceitos em particular, para conhecer e reconhecer melhor o acontecido, aquilo que passou e sobre o qual ela se debruça, com certa distância necessária mesmo que curta. Distância própria da reflexão, da autorreflexão, do examinar socrático (Apologia de Platão, 38 a). Em oposição a esse olhar retrospectivo e examinador que ela também pode adotar, naturalmente, a literatura também arriscaria, às vezes sem mesmo o saber, uma dimensão "profética", como diz W. Benjamin sobre $\mathrm{Kafka}^{9}$. Ela ousa falar daquilo que não aconteceu ainda, nesse sentido, daquilo que não existe, seja porque pertence a um futuro desconhecido, seja porque ela inventa outros mundos, imagina, enfim é ficção. Platão diria que ela é mentira. Hoje podemos relativizar esse juízo moralizante e dizer: sim, mas para inventar outras possibilidades de mundo, nesse sentido ela aponta para os possíveis e o porvir, não para o existente presente.

Essa dimensão ficcional e crítica encontra na reflexão hermenêutica de Paul Ricoeur sobre símbolo, metáfora e narrativa, uma defesa convicta daquela dimensão não

8 Observamos aqui que não dá para misturar essa reflexão sobre o trauma indizível com uma estética do sublime, segundo Kant; são dois fenômenos diferentes.

9 Ensaio de Benjamin intitulado "Franz Kafka. Beim Bau der chinesischen Mauer", In Gesammelete Schriften, II-2, pp. 676 seguintes. Não há tradução brasileira. 
referencial da literatura, se é que entendemos por "referência" unicamente e só a "adequação do discurso ao real". Ricoeur defende a tese da "reconfiguração mimética" do mundo pela literatura e, ao mesmo tempo, o questionamento dessa concepção única de relação referencial. Cito um trecho de uma entrevista:

Eu qualifico a função da refiguração [no texto literário] como mimética. Todavia, é extremamente importante não se enganar sobre sua natureza: ela não consiste em reproduzir o real, mas em reestruturar o mundo do leitor ao confrontá-lo com o mundo da obra (...). No plano filosófico, isso conduz a colocar em questão a concepção clássica de verdade como adequação ao real; pois, se podemos falar de verdade a propósito da obra de arte, é na medida em que designamos com isso sua capacidade de abrir um caminho no real, renovando-o segundo ela, por assim dizer. ${ }^{10}$

Assim, a arte e mais especificamente em Ricoeur a literatura colocam em questão a metafísica - e igualmente o senso comum - , uma vez que colocam em questão "a concepção clássica da verdade como adequação ao real". Longe de ser um simples divertimento ou uma distração agradável, a literatura, justamente porque é ficção, coloca em questão o real enquanto tal como critério exclusivo de verdade. A literatura nos permite uma ampliação e uma transformação da experiência humana.

É a "abolição do caráter de mostração ou ostentação da referência", abolição ainda mais manifesta no texto escrito que caracteriza justamente a literatura, em particular a ficção, e que sublinha o caráter ameaçador que a literatura pode, com efeito, ter com relação ao mundo "tal como ele é", a isso que Adorno chamaria talvez das Bestehende, o que existe como algo pretensamente dado. Ricoeur o diz com todas as letras: "Este parece ser o papel da maior parte de nossa literatura: o de destruir o mundo" 12 . Todavia, é justamente nessa destruição, ou de maneira menos provocadora, nas "metamorfoses" que ela suscita na percepção da realidade cotidiana, que reside a verdade da literatura. É justamente porque a literatura, em particular a ficção, não diz o mundo tal qual é (e isso mesmo na literatura dita realista!), porque ela reinventa o 10 Paul Ricoeur. La critique et la conviction, Calmann-Lévy,Paris, 1991, p.260-261. 
mundo, porque ela "mente" como o dizia Platão dos poetas, que ela permite o surgimento de outro tipo de verdade. Não se trata, então, de aproximar a ficção do real, mas, pelo contrário de pensar sua distância como o indício de um outro devir que a literatura pode nos fazer pressentir. O retirar-se da arte longe da realidade cotidiana, diz Ricoeur, é também a condição de sua "irrupção" nessa mesma realidade, ou seja, seu questionamento. Sem essa radicalidade, a arte "seria marcada por insignificância e reduzida a puro divertimento"13 - Adorno diria: reduzida à "indústria cultural".

Essa defesa intransigente daquilo que chamei num artigo de "dimensão ontológica da literatura" nos permite talvez enfrentar com menos medo as relações possíveis entre literatura e filosofia. Separadas por Platão para justamente permitir a nomeação de outro ideal de discurso, o logos filosófico, elas não precisam nem continuar inimigas irredutíveis nem ser assimiladas uma à outra numa grande confusão generosa e frouxa. Sua separação também persiste por razões históricas ligadas à diferenciação histórica das disciplinas, em particular no contexto do ensino escolar e universitário onde cada um defende seu território. Agora, nessa contextualização histórica, podemos estudar com proveito aquilo que Gottfried Gabriel (um filósofo alemão contemporâneo, especialista de Kant, Wittgenstein e Frege!) chamou, de maneira muito feliz, de "formas literárias da filosofia". Gabriel observa que essas formas específicas são imprescindíveis para o bom entendimento do texto filosófico, do seu "conteúdo", se quisermos ainda usar essa dicotomia antes de mostrar sua insuficiência. Exemplos: se Platão escreve diálogos (e não elabora um sistema totalizante), é justamente porque ele quer ressaltar que a filosofia é primeiramente um diálogo vivo entre interlocutores benevolentes, uma busca em comum. Se Montaigne inventa o gênero "Ensaios", é porque ele não pode mais edificar uma descrição dedutiva e racional, por ceticismo, claro, e pela natureza do seu objeto, esse "eu" multiforme. Mesmo Kant deve desistir da edificação completa de um sistema como o da razão pura quando se trata de compreender as regras da ação moral e as da arte. Depois de Nietzsche, quem de nós ainda ousaria escrever um sistema totalizante? O que não significa que somente os aforismos e os fragmentos por si nos garantem profundidade!

O movimento autorreflexivo da filosofia sobre seu caráter de linguagem, seu caráter linguístico ou linguageiro (sprachlich) no sentido amplo do termo, isto é, 
também sobre sua forma literária, permite, em termos de história da filosofia, uma leitura renovada, mais atenta à singularidade dos textos. G. Gabriel cita o exemplo do texto da "prova ontológica"; quando se lembra que o escrito de Anselmo é um tipo de oração (proslogion), o caráter de prova (onto)lógica não desaparece, mas passa a ter um outro peso, porque tratar-se-ia aqui muito mais de confirmar a própria fé do que de provar logicamente a necessidade da existência de Deus ${ }^{14}$.

Concluímos: filosofia e literatura são, ambas, disciplinas que vivem do enigma que permanece a respeito das relações entre linguagem e mundo. Talvez a filosofia queira, sim, ampliar a zona de clareza em redor do enigma - e para isso, a reflexão sobre suas formas retóricas e literárias só pode ajudar. Talvez a literatura consiga permanecer com mais tranquilidade na opacidade do enigma porque não pretende esclarecê-lo. Mas ela precisa lançar mão, para isso, de invenções e de figurações sempre renovadas, isto é, ela também precisa se aventurar pelos caminhos do pensamento.

Jeanne Marie Gagnebin, Campinas, setembro de 2015.

14 Gottfried Gabriel e Christiane Schildknecht, Literarische Formen der Philosophie, Metzler, 1990, p. 16. 